6 eventos 


\section{O Anos de pós-gRaduaçÃo E CENTENÁRIO DO EDIFÍCIO VILA PENTEAdO}

O ano de 2002 teve um significado especial para a FAUUSP, principalmente para seu curso de pós-graduação, situado no Prédio Vila Penteado. Especial porque este curso está completando 30 anos de atuação em prol do ensino e da pesquisa e, ao mesmo tempo, comemorando o centenário de seu edifício-sede, que pertenceu à família Álvares Penteado e foi doado à USP em 1946, sob condição de ali se instalar um curso específico de arquitetura. Até 1968, antes de se transferir para a Cidade Universitária, o curso de graduação permaneceu neste edifício público, posteriormente, tombado por órgãos do patrimônio histórico, artístico e cultural. Hoje é um dos raros edifícios art-nouveau que a cidade de São Paulo possui. O projeto original, de 1902, é do arquiteto sueco Carlos Ekman, que o fez a pedido da família Penteado.

Desde 1972, o Edifício Vila Penteado, também conhecido como FAUMaranhão, abriga o curso de pós-graduação em arquitetura e urbanismo da FAUUSP (mestrado e doutorado). O curso vem formando e recebendo profissionais de diferentes instituições nacionais e do exterior, principalmente da América Latina. Habitualmente, considerando-se professores, alunos, funcionários e visitantes, temos centenas de pessoas circulando e/ou participando do dia-a-dia da Escola.

No decorrer desse ano, vários eventos foram promovidos pela Comissão de Pós-Graduação. Sob a coordenação das Profas. Dras. Maria Ruth Amaral de Sampaio (diretora), Ermínia Maricato (presidente CPG) e Vera Pallamin (editorachefe de Revista Pós), realizou-se o Seminário 30 anos de pós-graduação: novos desafios, nos dias 28 e 29 de outubro, visando à divulgação das novas áreas de concentração, contando com significativa participação de docentes e alunos.

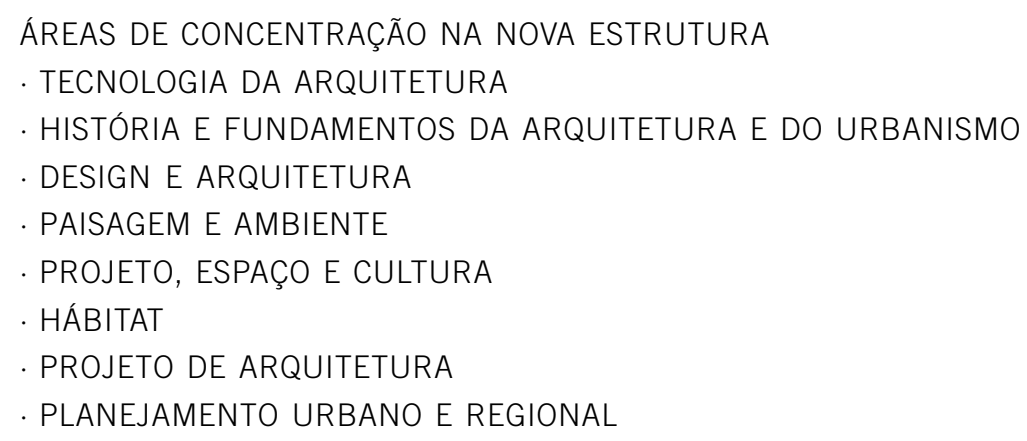

Como registro deste trabalho foi também editado o CD-ROM "30 anos de Pós-Graduação 1972-2002", que traz o histórico do curso, assim como resumo das teses e dissertações apresentadas nesse período com suas respectivas bancas examinadoras. 


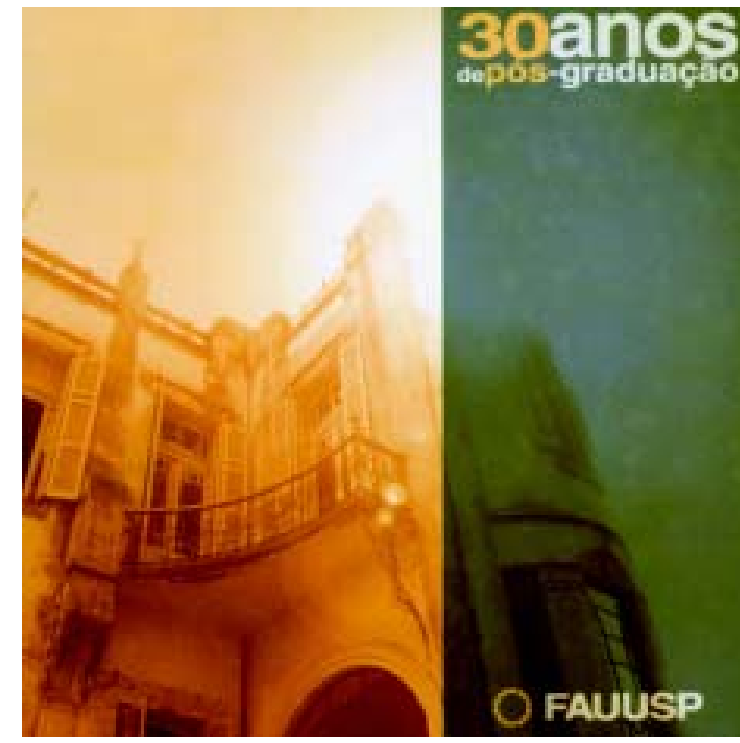

CD-ROM

30 Anos de Pós-Graduação

FAUUSP

Para comemorar o centenário do edifício foi realizado em 8 de novembro um debate público intitulado Vila Penteado: Cidade, História e Arquitetura, com a participação dos arquitetos Carlos Lemos, Júlio Katinsky e Paulo Mendes da Rocha. Nesse mesmo dia, aconteceu o lançamento dos livros Vila Penteado: 100 anos, vários autores, e Vila Penteado: Registros, de Benedito Lima de Toledo, assim como a cerimônia de reinauguração da Biblioteca Tereza Almarsio Hamel, sob a coordenação do professor Júlio Katinsky e da bibliotecária chefe, Eliana de Azevedo Marques, com patrocínio da Fapesp.
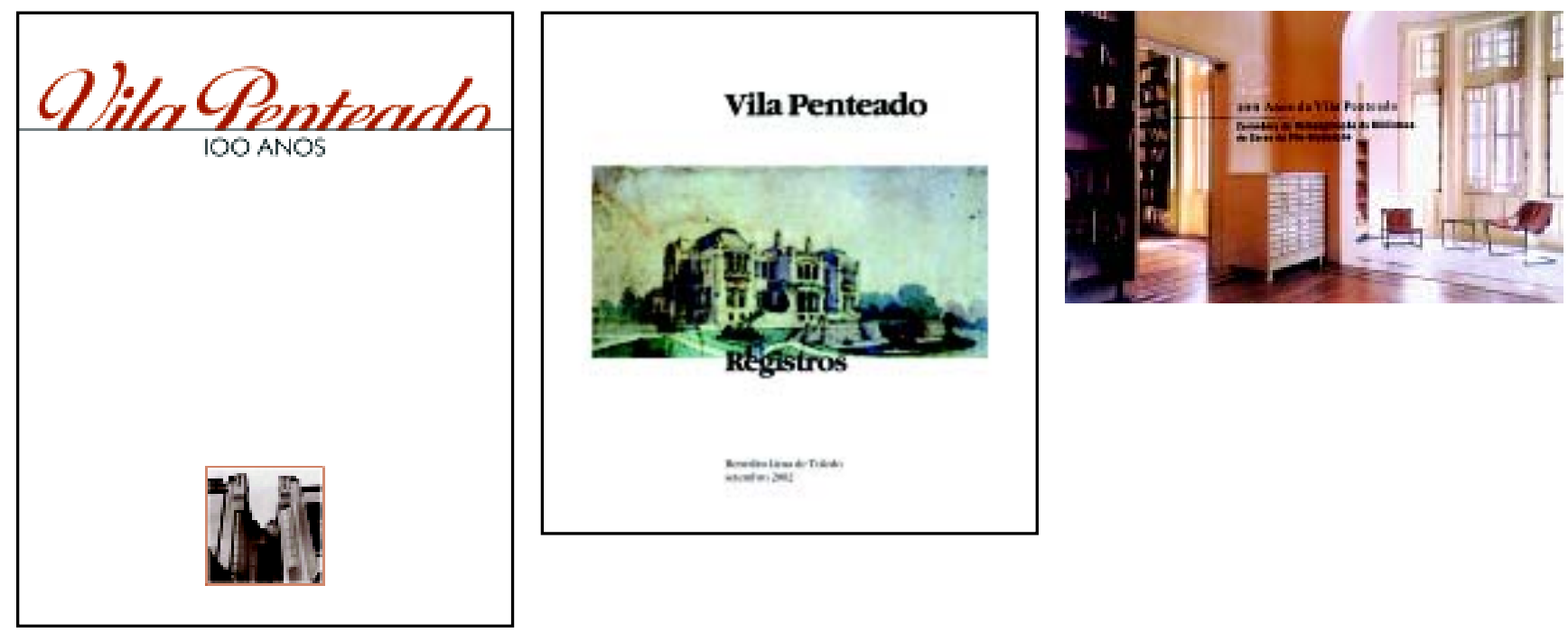
SEMINÁRIO

Centenário da Vila Penteado:

Restauração
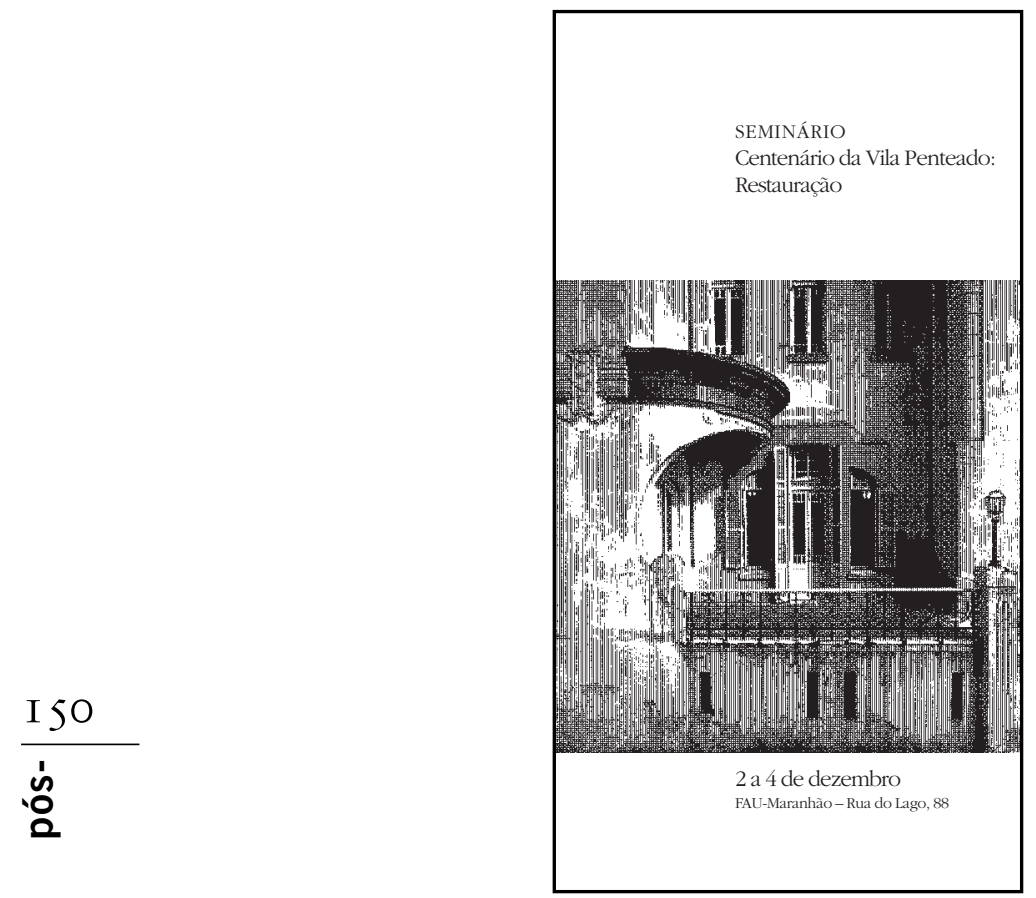

Ainda, na agenda de comemorações, a Diretoria da FAUUSP, com apoio do Departamento de História da Arquitetura e Estética do Projeto, promoveu 0 Seminário Centenário da Vila Penteado: Restauro, realizado nos dias 2, 3 e 4 de dezembro, com a participação de especialistas na área, professores, alunos e profissionais ligados aos órgãos públicos da cidade.

Esses importantes eventos tiveram apoio das Pró-Reitorias de Pós-Graduação e de Cultura e Extensão Universitária da USP.

Lina Rosa

Nota:

Os interessados em adquirir os livros sobre a Vila Penteado ou o CD-ROM sobre o curso de pós-graduação, assim como outros títulos da FAUUSP, poderão solicitar em: www.fupam.com.br > livraria. 